УДК 621.793.72

\title{
ФАКТОРЫ, ВЛИЯЮЩИЕ НА ПРОЦЕСС ФОРМИРОВАНИЯ СТРУКТУРЫ И СВОЙСТВ ПОКРЫТИЙ ПРИ ЭЛЕКТРОДУГОВОМ НАПЫЛЕНИИ
}

\author{
Борисова Мария Захаровна \\ K.T.H., с.H.C. \\ ФГБУН ФИЦ «ЯНЦ СО РАН» \\ Институт физико-технических проблем \\ Севера им. В.П. Ларионова СО РАН
}

\begin{abstract}
Аннотация: Метод электродугового напыления позволяют наносить покрытия различных металлических сплавов, повышающих износостойкость, прочность и долговечность деталей машин. В статье рассмотрены различные факторы, влияющие на формирование напыленных покрытий и их и свойства. Показано, что покрытия, полученные электродуговым напылением характеризуются неоднородной структурой, состоящей из послойно уложенных сплэтов, нерасплавленных частиц металла и оксидных образований. Формирование напыленных покрытий зависит от различных факторов: характеристики транспортирующего газа, распыляемого материала, дистанции напыления, энергетических показателей и подготовки напыляемой поверхности.
\end{abstract}

Ключевые слова: порошковая проволока, дуговая металлизация, наплавка, структура, износостойкость.

\section{FACTORS INFLUENCING THE FORMATION OF THE STRUCTURE AND PROPERTIES OF COATINGS DURING ELECTRIC ARC SPRAYING}

\section{Borisova Maria Zaharovna}

\begin{abstract}
The method of electric arc spraying makes it possible to apply coatings of various metal alloys that increase the wear resistance, strength and durability of machine parts. The article discusses various factors affecting the formation of sprayed coatings and their properties. It is shown that the coatings
\end{abstract}




\section{СОВРЕМЕННЫЕ ТЕХНОЛОГИИ:

obtained by electric arc spraying are characterized by an inhomogeneous structure consisting of layered splats, non-molten metal particles and oxide compoundes. The formation of sprayed coatings depends on various factors, such as the characteristics of the transporting gas, the sprayed material, the spraying distance, energy indicators and the preparation of the substrat sureface.

Key words: powder wire, arc metallization, structure, wear resistance.

Для увеличения срока службы, а также восстановления деталей машин, работающих в условиях интенсивного изнашивания широко применяются методы дуговой металлизации и наплавки [1-3]. Имеющееся на сегодняшний день оборудование для электродугового напыления позволяют наносить покрытия различных металлических сплавов, повышающих износостойкость, прочность и долговечность деталей машин (рис. 1). Данный метод является одним из самых технологичных, производительных и качественных методов. Область применения достаточно широка: восстановление стальных, чугунных и изготовленных из цветных металлов изделий; деталей цилиндрической и плоской формы, работающих в условиях трения скольжения, смазки и неподвижных посадок; возможность исправления дефектов стального и чугунного литья; увеличение жаростойкости стали; напыление антифрикционных покрытий и т. д [4-6]. К преимуществам электродугового напыления относятся: высокая производительность нанесения покрытия; получение покрытия толщиной 0,1-10 мм; износостойкость в 1,5-2 раза выше, чем у закаленной стали.

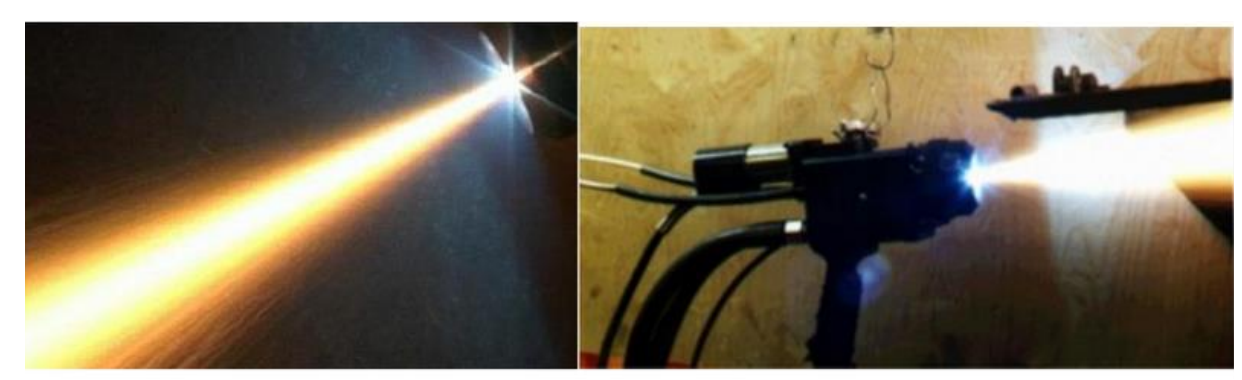

Рис. 1. Процесс электродугового напыления [5]

К факторам, оказывающим влияние на формирование структуры и свойства покрытий, относятся: величина тока; используемый газ, его давление и расход; диаметр и форма сопла; дистанция напыления; скорость перемещения металлизатора; диаметр проволоки, её химический состав [7] и скорость подачи 


\section{СОВРЕМЕННЫЕ ТЕХНОЛОГИИ:

(рис. 2). Также важным параметром является подготовка напыляемой поверхности, её шероховатость и температура подогрева.

При изменении различных факторов процесса напыления изменяются также диаметр, скорость и температура расплавленных частиц, степень их окисления; степень активации, что в свою очередь влияет и на изменение структуры получаемого покрытия и его свойства. Повышение давления распыляющего газа способствует росту адгезии покрытия и уменьшению пористости [9-10].

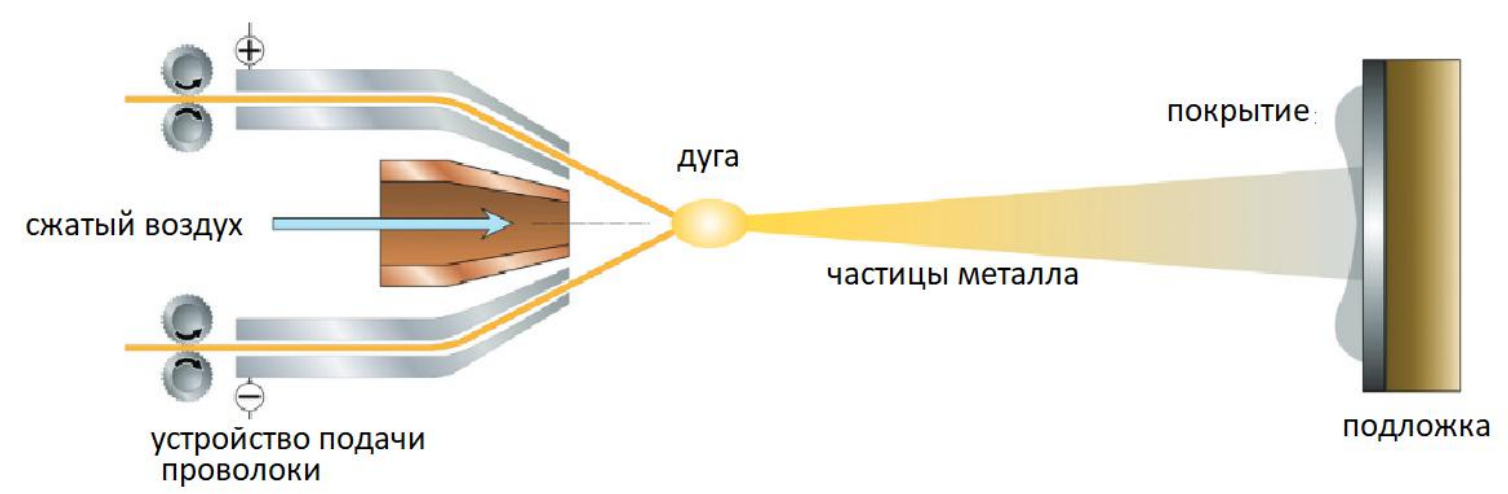

\section{Рис. 2. Схема процесса электродугового напыления}

Структура напыленного покрытия представляет собой сложную систему, состоящую из различных фаз, отличающихся по химическому и фазовому составу. Сжатый газ транспортирует расплавленные частицы к подложке, где они расплющиваются и перемешиваются. В результате формируется слоистая микроструктура (рис. 3).

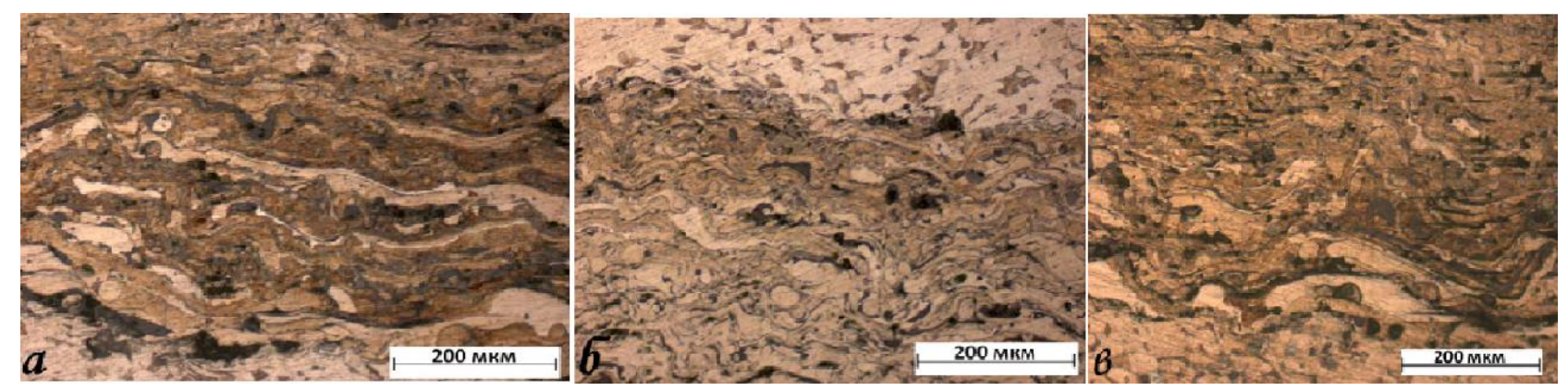

Рис. 3. Микроструктура газотермических покрытий, полученных при разной величине напряжения дуги 
Рост напряжения дуги приводит к уменьшению расплавленных частиц и формированию более тонких слоев. Такое же влияние оказывает увеличение давления транспортирующего газа, но при этом увеличивается также выгорание частиц напыляемого материала. При увеличении дистанции напыления происходит рост скорости частиц, но при этом растет и степень окисления. Рекомендуемая дистанция напыления 80-150 мм. Эксплуатационные свойства покрытий из порошковых проволок выше, чем у гомогенных, компоненты порошковой шихты активно взаимодействуют друг с другом и обрабатываемой поверхностью при напылении. Предварительная обработка обрабатываемой поверхности обеспечивает надежное сцепление покрытия с подложкой. Обработка дробью обеспечивает шероховатую, чистую поверхность с высокой адгезией и повышает предел выносливости основного металла.

\section{Список литературы}

1. Кудинов В.В., Пекшев П.Ю., Белащенко В.Е., Солоненко О.П., Сафиуллин В.А. Нанесение покрытий плазмой. М.: Наука, 1990. 408 с.

2. Тушинский Л.И., Плохов А.В. Исследование структуры и физико-механических свойств покрытий. Новосибирск: Наука, 1986. 200 с.

3. Кипарисов С.С., Либенсон Г.А. Порошковая металлургия. М.: Металлургия, 1991. 432 с.

4. Коробов Ю.С. Эффективность применения активированной дуговой металлизации для нанесения защитных покрытий // Сварочное производство. 2005. No 2. C. 47-50.

5. Коробов Ю.С., Вихлянов М.В., Гончаров С.Н., Макаров А.В., Потехин Б.А., Прохорович В.Е., Разиков Н.М., Филиппов М.А., Шумяков В.И. Экономнолегированные порошковые проволоки для сварки, наплавки, напыления в износостойких и высокотемпературных применениях// Сборник докладов III Всероссийской научно-технической конференции. ФГУП «ВИАМ». Роль фундаментальных исследований при реализации "стратегических направлений развития материалов и технологий их переработки на период до 2030 года. 2016. С.

6. Коробов Ю.С., Шумяков В.И., Филиппов М.А., Невежин С.В. Разработка порошковых проволок для получения покрытий, стойких к износу и газовой коррозии. // Сварщик в России. - 2012. - № 4. - С. 8-10. 
7. Винокуров Г.Г., Кычкин А.К., Яковлева С.П., Махарова С.Н., Стручков Н.Ф. Использование минеральных модифицирующих добавок в износостойких электрометаллизационных покрытиях и порошковых проволоках // Технология металлов. 2008. № 10. C. 28-33.

8. Shapovalov A.N., Kalugina O.B., Dema R.R. Investigation of the structure of wear resistant coatings obtained by plasma powder surfacing. MATEC Web of Conferences 129(02044). 2017. P. 1-6.

9. Logachev V.N., Kolomeichenko A.V., Kuznetsov Yu.A., Solovev R.Yu., Denisov V.I., Sharifullin S.N. Aerosol fluxing in electro arc metallization//International scientific-technical conference on innovative engineering technologies, equipment and materials 2016, ISTC-IETEM 2016. IOP Conf. Series: Materials Science and Engineering 240 (2017) P. 012049.

10. Kolomeichenko A.V., Kravchenko I.N., Logachev V.N., Litovchenko N.N., Puzryakov A.F. Improvement of physical and mechanical properties of coatings obtained by electroarc metallization // Construction and road machines. № 7 . P. 25-29.

(C) М.3. Борисова, 2021 